\title{
TFF2, a MUC6-binding lectin stabilizing the gastric mucus barrier and more (Review)
}

\author{
WERNER HOFFMANN \\ Institute of Molecular Biology and Medicinal Chemistry, \\ Otto-von-Guericke-University Magdeburg, D-39120 Magdeburg, Germany
}

Received June 16, 2015; Accepted July 7, 2015

DOI: $10.3892 /$ ijo.2015.3090

\begin{abstract}
The peptide TFF2 (formerly 'spasmolytic polypeptide'), a member of the trefoil factor family (TFF) containing two TFF domains, is mainly expressed together with the mucin MUC6 in the gastric epithelium and duodenal Brunner's glands. Pathologically, TFF2 expression is observed ectopically during stone diseases, chronic inflammatory conditions and in several metaplastic and neoplastic epithelia; most prominent being the 'spasmolytic polypeptide-expressing metaplasia' (SPEM), which is an established gastric precancerous lesion. TFF2 plays a critical role in maintaining gastric mucosal integrity and appears to restrain tumorigenesis in the stomach. Recently, porcine TFF2 has been shown to interact with the gastric mucin MUC6 and thus stabilize the gastric mucus barrier. On the one hand, TFF2 binds to MUC6 via non-covalent lectin interactions with the glycotope GlcNAc $\alpha 1 \rightarrow 4 \mathrm{Gal} \beta 1 \rightarrow \mathrm{R}$. On the other hand, TFF2 is probably also covalently bound to MUC6 via disulfide bridges. Thus, implications for the complex multimeric assembly, cross-linking, and packaging of MUC6 as well as the rheology of gastric mucus are discussed in detail in this review. Furthermore, TFF2 is also expressed in minor amounts in the immune and nervous systems. Thus, similar to galectins, its lectin activity would perfectly enable TFF2 to form multivalent complexes and cross-linked lattices with a plethora of transmembrane glycoproteins and thus modulate different signal transduction processes. This could explain the multiple and diverse biological effects of TFF2 [e.g., motogenic, (anti)apoptotic, and angiogenic effects]. Finally, a function during fertilization is also possible for TFF domains because they occur as shuffled modules in certain zona pellucida proteins.
\end{abstract}

Correspondence to: Dr Werner Hoffmann, Institute of Molecular Biology and Medicinal Chemistry, Otto-von-Guericke-University Magdeburg, Leipziger Str. 44, D-39120 Magdeburg, Germany E-mail: werner.hoffmann@med.ovgu.de

Key words: lectin, mucus, mucin, MUC6, TFF2, trefoil factor, gastric mucosa, gastric cancer, SPEM, stomach, von Willebrand factor

\section{Contents}

1. Introduction

2. TFF2 and its function in the gastric mucus barrier

3. Conclusions and future perspectives

\section{Introduction}

Mucous epithelia cover the inner surfaces of our body and are essential for interaction with the outside world (e.g., respiration, uptake and digestion of food, excretion, reproduction, visual and auditory systems). These delicate epithelia are exposed to a myriad of noxious agents and thus rely on multiple mucosal protection and defense mechanisms (1), including the: i) mucosal barrier (i.e., the extracellular mucous gel, the apical glycocalyx, and the polarized epithelium connected by tight junctions), ii) secretion of antimicrobial peptides, iii) rapid repair by cell migration (restitution), iv) continuous self-renewal by differentiation from stem and precursor cells, and v) an acute inflammatory response. For the structure and function of the extracellular viscoelastic mucous gel, i.e., the mucus, both secretory mucins (MUC2, MUC5AC, MUC5B, MUC6, MUC19) as well as trefoil factor family (TFF) peptides play key roles (2-5). Protection of the stomach epithelium is a unique problem because of the acidic $\mathrm{pH}$ of the gastric juice. Thus, the mucous gels covering the gastric surface mucosa and its glands, respectively, have a special composition designed to optimally fulfill their physiological function(s). Here, the function of TFF2 for the gastric mucus barrier is discussed.

TFF2, a gastroduodenal mucus constituent and more. TFF2 (originally termed 'pancreatic spasmolytic peptide') is a 106 amino acids containing secretory peptide conserved from birds to human containing two TFF domains (reviewed in refs 4-6). Of special note, the TFF domain (7), in the past often also referred to as 'trefoil domain', is not related to the ' $\beta$-trefoil fold' found in certain lectins. Each of the two TFF domains contains one conserved tryptophan and 6 conserved cysteine residues forming 3 disulfide bridges. Furthermore, a seventh disulfide bridge links Cys $^{6}$ and Cys $^{104}$ (Fig. 1) $(8,9)$. This is probably the reason why TFF2 is stable in the gastric juice (4). Human gastric TFF2 is N-glycosylated containing a fucosylated N,N'-diacetyllactosediamine (LacdiNAc) oligo- 
saccharide (10); in contrast, the porcine, murine, and rat TFF2 lack N-glycosylation sites. Thus far, the functional significance of the fucosylated LacdiNAc structure in human TFF2 is not known but it might influence microbial colonization (e.g., by Helicobacter pylori) particularly of the antrum (10). Neither is it known currently, if the fucosylated LacdiNAc structure is recognized by galectins, in particular by galectin-3. Interestingly, porcine pancreatic TFF 2 forms non-covalently linked dimers in the solid phase $(9,11)$ as well as in solution (12); the latter being unusually resistant even to boiling SDS (12).

TFF2 is typically co-secreted with the mucin MUC6 from gastric fundic and antral glands (mucous neck and antral gland cells, respectively) as well as duodenal Brunner's glands (13-17) and represents a characteristic constituent of the gastroduodenal mucus (18). Of special note, in the gastric fundic glands TFF2 mRNA and protein do not co-localize. TFF2 transcripts are detectable in mucous neck cell progenitors only. This has been shown for human (19), mouse (20), and rat (21). TFF2 also appears as a constituent of the gastric juice with dramatic diurnal variations (22). In the pig, in contrast to human, TFF2 is also abundantly secreted from exocrine pancreatic glands (acinar cells) (14). Furthermore, TFF2 is expressed in salivary glands $(21,23)$.

Other than in mucous epithelial glands, TFF2 is also expressed in the immune and the central nervous systems (CNS). For example, TFF2 is found in macrophages and lymphocytes $(24,25)$ as well as in the anterior pituitary and the developing brain (26).

TFF2 is an early response gene after gastric mucosal injury (27). During various chronic inflammatory conditions, TFF2 is expressed ectopically in the ulcer-associated cell lineage (28-30). Furthermore, pathological expression of TFF2 occurs in several metaplastic and neoplastic epithelia (compilations in refs. 4,17,30,31), most prominent being the spasmolytic polypeptide-expressing metaplasia (SPEM), which is found at the base of gastric fundic units as a consequence of dysregulated trans-differentiation of zymogenic cells as well as arrest of mucous neck cell trans-differentiation into zymogenic cells $(32,33)$. SPEM gives rise to intestinal metaplasia and is even more strongly associated with gastric cancer than is intestinal metaplasia (34).

In the past, TFF2 was considered as a protective rapid response peptide $(27,35)$ responsible for epithelial repair due to its relatively weak motogenic effects in vitro and moderate protective or healing effects in vivo (compilations in refs. 4,31). Detailed comparative studies demonstrated that only luminal, but not parenteral TFF2 was protective in one out of two colitis models in vivo (36). This is in line with a report that delivery of TFF 2 by genetically modified Lactococcus lactis prevents and heals acute colitis in mice (37). The weak motogenic effect is a chemotactic effect and is dependent on the ERK1/2 pathway $(38,39)$. Furthermore, also (anti)apoptotic and angiogenic effects have been reported for TFF2 $(4,5,31)$. However, all attempts have so far failed to convincingly demonstrate a typical transmembrane receptor for TFF2. Currently, TFF2 is considered a low affinity ligand for the chemokine receptor CXCR4 $(40,41)$. Furthermore, integrin $\beta 1$ as well as a large transmembrane glycoprotein with similarity to CRP-Ductin/ DMBT1/gp-340/hensin have been identified as TFF2 binding proteins in the porcine stomach (42). Interestingly, intravenously administered TFF2 was taken up by mucous neck cells, parietal cells, and pyloric gland cells and subsequently appeared in the mucus layer (43). This could be an indication for receptor-mediated transcytosis.

In contrast to the abundant synthesis of TFF2 in the stomach, Tff2-deficient ( $\mathrm{Tff} 2^{\mathrm{KO}}$ ) mice show surprisingly moderate gastric phenotypes. Tff $2^{\mathrm{KO}}$ mice had increased susceptibility to Helicobacter felis-induced gastritis (25), they showed accelerated progression of gastritis to dysplasia in the antrum (44), and laser-induced photodamage of the gastric surface epithelium resulted in an attenuated alkalization of the surface $\mathrm{pH}$ in these animals (45). Furthermore, $\mathrm{Tff} 2^{\mathrm{KO}}$ mice showed an altered expression of genes implicated in the immune system (46), they were hyperresponsive to interleukin-1 $\beta$ stimulation (25), exhibited increased susceptibility to Yersinia enterocolitica infection (47), and displayed reduced gut immunopathology after oral infection with Toxoplasma gondii (48). Taken together, $\mathrm{TFF} 2^{\mathrm{KO}}$ mice show both gastric and immunological phenotypes.

The extracellular gastric mucus barrier. The gastric mucusbicarbonate-phospholipid barrier is a viscoelastic gel acting as the first line of defense against chemical, physical, and biological insults $(1,49,50)$. The secretory gel-forming mucins MUC5AC and MUC6 are major constituents of the gastric cell surface mucus barrier (3). These heavily O-glycosylated, expanded glycoconjugates confer viscous properties due to the enormous length of mainly linear mucin homo-oligomers and their extreme hydration (2). MUC5AC is secreted by surface mucous and pit cells of the gastric mucosa (Fig. 2) (51-53). Of special note, MUC5AC in the mid and lower pit regions is sulfated (Fig. 2) (54). In contrast, MUC6 is typically secreted by the gastric glands, i.e., mucous neck cells in fundic glands as well as antral gland cells (Fig. 2) (52,53). Interestingly, MUC6 is aberrantly expressed in surface mucous cells in $H$. pyloriinfected patients (55). Gastric MUC6 is characterized by the specific carbohydrate moiety GlcNAc $\alpha 1 \rightarrow 4 \mathrm{Gal} \beta 1 \rightarrow \mathrm{R}$ at non-reducing terminals (56). A key enzyme for formation of this epitope is the $\alpha 1,4-\mathrm{N}$-acetylglucosaminyltransferase $(\alpha 4 \mathrm{GnT})$ (57). This enzyme plays an essential role for gastric protection as mice lacking this enzyme (A4gnt $\left.{ }^{\mathrm{KO}}\right)$ typically show gastric mucosal inflammation and spontaneously develop adenocarcinoma exclusively in the gastric antrum through a hyperplasia-dysplasia-carcinoma sequence in the absence of H. pylori infection (58). The GlcNAc $\alpha 1 \rightarrow 4 \mathrm{Gal} \beta 1 \rightarrow \mathrm{R}$ moiety is recognized by the lectin GSA-II binding to the terminal GlcNAc (59), the monoclonal antibody HIK1083 (56), and paradoxical concanavalin A staining (60). Of note, GSA-II prevented the subsequent binding of HIK1083 (59).

Gastric mucins MUC5AC and MUC6 also differently regulate colonization with $\mathrm{H}$. pylori (61). For example, $H$. pylori colonizes the MUC5AC layers of the gastric mucus (62-64). In contrast, the MUC6 layers are barely colonized because the terminal $\alpha 1,4-$ GlcNAc of the MUC6 carbohydrate moiety has an antimicrobial activity against $H$. pylori by inhibiting the biosynthesis of cholesteryl- $\alpha$-D-glucopyranoside, an essential cell wall constituent of $H$. pylori $(58,65)$.

Furthermore, the membrane-tethered mucin MUC1, which is also capable of intracellular signaling, is found on the apical 
TFF2

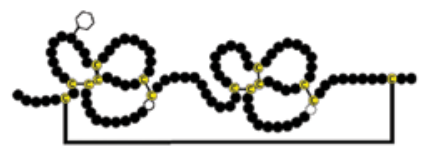

XP4

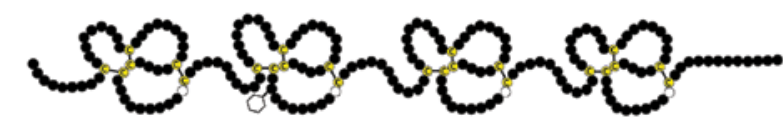

Figure 1. Schematic representation of the structure of mammalian TFF2 and amphibian xP4 consisting of 106 and 207 amino acids, respectively. Shown are the conserved cysteine residues (yellow) including their disulfide bridges as well as the conserved tryptophan residues (white) characteristic of each TFF domain. The $\mathrm{N}$-glycosylation sites in human TFF2 and in xP4.1 from X. laevis are indicated by hexagons.
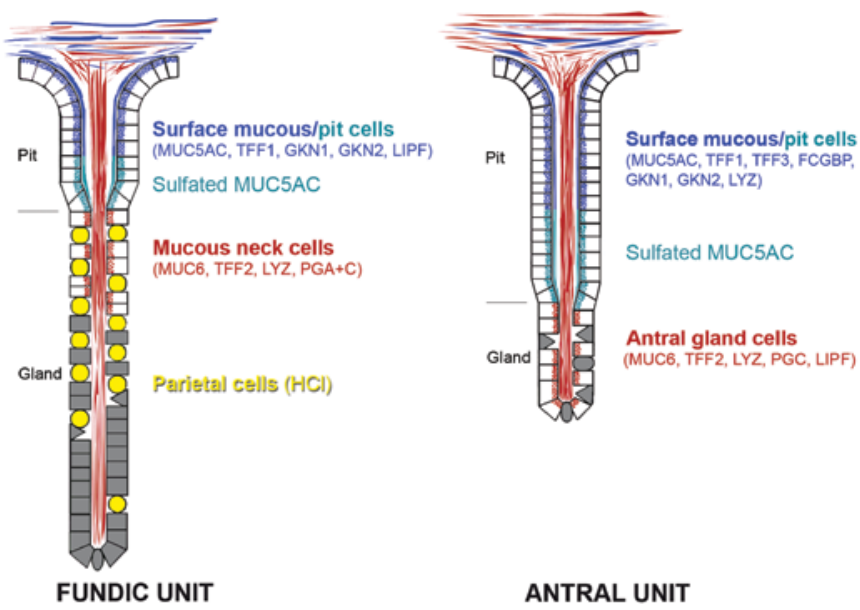

Figure 2. Schematic representation of human fundic and antral units and the excretory flow of gastric mucus. The layered mucus structure at the gastric mucosal surface consists of an alternating array of MUC5AC (blue; secreted from both surface mucous and pit cells) and MUC6/TFF2 (red; both originating from mucous neck and antral gland cells, respectively). Of note, MUC5AC in the mid and low pit regions is sulfated (54). Also shown are the major secretory products of the mucous cells such as mucins (MUC), TFF peptides, IgG Fc binding protein (FCGBP), gastrokines (GKN), gastric lipase (LIPF), lysozyme (LYZ), and pepsinogens (PGA, PGC). The hydrochloric acid $(\mathrm{HCl})$ producing parietal cells are colored yellow.

side of surface mucous cells and in the mucous neck cell zone (66). In addition to tethering the mucus to the epithelial surface, MUC1 is a sensor of the environment including microorganisms and it can be shed from the cell surface (67). Of note, $\mathrm{Muc}^{\mathrm{KO}}$ mice have thinner gastric mucus layers (68). MUC13 is another membrane-tethered mucin expressed in the surface epithelium as well as in gastric glands (69).

In addition to the gel-forming mucins MUC5AC and MUC6 as well as a variety of ions (e.g., $\mathrm{H}^{+}, \mathrm{Na}^{+}, \mathrm{Ca}^{2+}, \mathrm{Mn}^{2+}$, $\left.\mathrm{Cu}^{2+}, \mathrm{Cl}^{-}, \mathrm{HCO}_{3}^{-}\right)$, gastric mucus also contains a complex mixture of additional proteins such as $\operatorname{sgA}, \operatorname{IgG}, \operatorname{IgM}(67)$, TFF peptides (5), gastrokines (70), IgG-Fc-binding protein (FCGBP) (19), DMBT1/gp-340 (71), galectins (72), $\beta$-defensins (73), cathelicidin LL-37/hCAP18 (74), lysozyme (19), and the extremophilic gastric lipase (75), which binds optimally to lipid-water interphases at low $\mathrm{pH}$. On top, the luminal surface of the gastric mucus seems to be coated with a hydrophobic film of surfactant phospholipids $(1,76,77)$. We are only at the beginning in the understanding of how these proteins interact and form a viscous gel matrix. Certainly, a complex interplay of different transient and non-transient interactions is involved to build up a complex network (78).

The viscous gastric mucus barrier has multiple physiological functions: this biofilm lubricates the passage of undigested food, protects the epithelium from mechanical damage and pepsin digestion, it is essential for maintaining a $\mathrm{pH}$ gradient towards the acidic gastric juice, and it supports and also restricts the adhesion and colonization of microorganisms (such as H. pylori) (49).

In rats, the mucus covering the gastric mucosa has been described as being composed of two layers, i.e., a loosely adherent (outer) layer, which can be removed by gentle suction, and a firmly adherent (inner) layer attached to the epithelium $(68,79)$. The thickness of the latter has been reported to be approximately 80 and $154 \mu \mathrm{m}$ in the corpus and antrum, respectively (79). The loosely adherent layer had a similar thickness and is not present in all rats (79). One possibility is that it may be rubbed off after food intake. Mice have a significantly thinner firmly adherent mucus layer compared with rats (68). This inner mucus layer can only be removed after application of a strong force and it is penetrable to beads the size of bacteria (80). In contrast to the colon, only small amounts of the murine gastric outer mucus layer could be removed by gentle aspiration (80). Muc5ac is a major component in both the firmly and loosely adherent mucus layers in mice (68).

In human as well as in the rat (54), the firmly adherent, water-insoluble gastric mucus layer (mean thickness: $44 \mu \mathrm{m}$ ) is composed of an alternating laminated array of two types of mucin, i.e., MUC5AC and MUC6 $(18,62,81,82)$. Furthermore, there is also soluble mucus mixed with the luminal gastric juice $(49,83)$.

The firmly adherent gastric mucus layer, and not the loosely adherent layer, is important for the maintenance of a $\mathrm{pH}$ gradient across the mucus layer (84). There are numerous reports of a $\mathrm{pH}$ gradient across the gastric mucus barrier with near neutral $\mathrm{pH}$ at the mucosal surface $(50,84,85)$. It is generally accepted that the buffering of the $\mathrm{H}^{+}$from the gastric juice occurs in the mucus via $\mathrm{HCO}_{3}{ }^{-}$, which is actively released from gastric surface mucous cells via an apical $\mathrm{Cl}^{-} / \mathrm{HCO}_{3}{ }^{-}$exchanger (50).

Another interesting point discussed repeatedly is, how can hydrochloric acid, i.e., $\mathrm{H}^{+}$and $\mathrm{Cl}^{-}$ions, be secreted across the mucus layer in order to reach the gastric juice (50). In the past, temporary canals have been reported in the mucous layer (86); there are also studies which failed to show these channels (50). However, ultrastructural studies of the excretory flow of gastric glands clearly described the merging of zymogenic contents with MUC6 and the development of laminated mucus structures at the surface (54). Based on the penetrability using beads (80) as well as on in vivo studies (50), there is clear evidence that the firmly adherent mucus layer is freely permeable to ions and small molecules.

\section{TFF2 and its function in the gastric mucus barrier}

TFF2 interacts with the mucin MUC6. TFF2 is an integral part of the laminated gastric mucus barrier. This has been clearly demonstrated by immunohistochemistry where TFF2 is asso- 
ciated with the gland mucin layers, i.e., MUC6, and not with layers representing the surface cell mucin MUC5AC (18). The association of TFF2 with mucins was also observed after size exclusion chromatography of both human and porcine gastric mucosa extracts. Here, TFF2 exclusively appeared in the highmolecular mass mucus fraction $(10,12,87)$. Furthermore, after anion exchange chromatography and non-reducing non-denaturing agarose gel electrophoresis TFF2 was predominantly associated with the mucin MUC6 in the porcine stomach forming an ultra-high molecular mass complex hardly entering the gel (12). Of special note, the porcine TFF2-MUC6 complex had an even higher $M_{r}$ than MUC5AC (12), which is in line with a previous report that also native human MUC6 appeared to be of larger size than MUC5AC (52).

In contrast, gel electrophoresis under reducing denaturing conditions easily released monomeric TFF2 from MUC6 (12). However, after non-reducing denaturing gel electrophoresis both a high molecular mass TFF2 heteromer as well as monomeric TFF2 were observed (12). This indicates that in the porcine stomach TFF2 is bound to MUC6 in part covalently by disulfide bridges and in part non-covalently. Thus, a lectin activity of TFF2 was predicted to be responsible for its non-covalent binding to MUC6, particularly to its characteristic structure GlcNAc $\alpha 1 \rightarrow 4 \mathrm{Gal} \beta 1 \rightarrow \mathrm{R}$ (12). Of note, based on its crystal structure a lectin activity cross-linking mucins have already been discussed for TFF2 (9). In particular, two hydrophobic clefts have been identified, one within each TFF domain, and all conserved residues are localized in their vicinity; two monosaccharides have been suggested to fit into each groove with the highly conserved $\operatorname{Trp}^{45}$ and $\operatorname{Trp}^{94}$ (Fig. 1) being very important residues in these binding pockets (11).

Non-covalent lectin interactions of TFF2 and MUC6. Based on these results, the sugar epitope responsible for TFF2 binding was characterized in more detail. With the help of TFF2 fusion proteins, the carbohydrate specificity was narrowed down in a porcine gastric mucin preparation to GlcNAc $\alpha 1 \rightarrow 4 \mathrm{Gal} \beta 1 \rightarrow 4 \mathrm{GlcNAc} \beta$ with only minor crossreactivity to GlcNAc $\alpha 1 \rightarrow 4 \mathrm{Gal} \beta$, which points to an extended glycotope that comprises more than a common disaccharide (88). The GlcNAc $\alpha 1 \rightarrow 4$ Gal $\beta 1 \rightarrow 4$ GlcNAc $\beta$ glycotope has been described previously as part of core 2 mucin structures from human and porcine stomach $(56,89)$ as well as from duodenal Brunner's glands, which also secrete MUC6 (90).

Lectin binding using TFF2 fusion proteins has been reported as being $\mathrm{Ca}^{2+}$-independent (88). This would be unusual as many lectins are calcium-dependent (91). However, studies with TFF2 purified from porcine pancreas suggest that its lectin activity is modulated by $\mathrm{Ca}^{2+}$. For example, binding of ${ }^{125} \mathrm{I}$-labeled TFF2 to FPLC-purified gastric mucus preparations from $\mathrm{Tff}^{\mathrm{KO}}$ mice immobilized on a CNBr-activated Sepharose ${ }^{\mathrm{TM}}$ 4B column depends on $\mathrm{Ca}^{2+}$ (Stürmer and Hoffmann, unpublished data). Furthermore, binding of ${ }^{125}$ I-labeled TFF2 to FPLC-purified gastric mucus preparations after gel electrophoresis and western blotting is reduced in the absence of $\mathrm{Ca}^{2+}$ (Richter, Stürmer and Hoffmann, unpublished data).

Possible covalent interactions of TFF 2 and MUC6. Other than as a lectin, TFF 2 is probably also covalently bound via disulfide bridges to the cysteine-rich domains of MUC6 at least in the porcine gastric mucus (12). The latter would be reminiscent to the formation of TFF1-GKN2 and TFF3-FCGBP heteromers $(87,92,93)$ and could particularly cross-link MUC6 dimers via an inter-molecular TFF2 bridge. However, TFF2 contains an even number of cysteine residues forming 7 disulfide bridges; thus, at least one disulfide bridge must be opened in order to enable formation of a heteromer. Of special note, the linkage between $\mathrm{Cys}^{6}$ and $\mathrm{Cys}^{104}$ (Fig. 1) has been reported to be particular sensitive to reduction (94) making this disulfide bridge the most likely candidate. Thus, the question arises, which cysteine residues of MUC6 could form a heteromer with TFF2.

Human MUC6 is a 2439 amino acid residue long protein (pre-pro numbering, Fig. 3) with a mosaic structure typical of the human secretory mucins MUC2, MUC5AC, MUC5B, and MUC19 and the frog integumentary mucin FIM-B.1 (2,95-97). The cysteine-rich domains have similarities to von Willebrand factor (vWF). MUC6 consists of a cysteine-rich N-terminal domain (D1D2D'D3), a highly O-glycosylated domain rich in proline, threonine and serine residues (PTS), and a C-terminal cystine knot (CTCK) domain (Fig. 3) (95). Native MUC6 is known to form large oligomeric complexes (52) and both the $\mathrm{N}$-terminal as well as the C-terminal cysteine-rich domains are essential for its oligomerization (98).

The N-terminal D1D2D'D3 domain of MUC6 (Fig. 3) contains an odd number of Cys residues (i.e., 97), triggers MUC6 oligomerization (98) and shows striking similarity to the assembly domain of vWF (particularly conserved Cys and Trp residues). In vWF, this domain is responsible for dimeric N-to-N assembly between juxtaposed D3 domains via two homophilic inter-molecular disulfide bridges, i.e., Cys ${ }^{1142}$-Cys ${ }^{1142}$ and Cys ${ }^{1099}$-Cys ${ }^{1099}(99,100)$. In contrast to the standard formation of disulfide bridges, which is restricted to the endoplasmic reticulum, D3 assembly occurs via a rearrangement of disulfide bonds in the acidic environment of the trans-Golgi network. This process depends on an intrinsic oxidoreductase activity of $\mathrm{vWF}(\mathrm{CxxC}$ motifs in $\mathrm{D} 1, \mathrm{D} 2$, and D3) $(99,101)$. However, the D1D2D'D3 assembly domain of MUC6 shows some characteristic features, which distinguish it from vWF (Fig. 3). For example, the sub-domain C8-2 in MUC6 lacks two conserved Cys residues, but contains an additional Cys residue at position 587, which is not conserved in vWF and the secretory mucins MUC2, MUC5AC, MUC5B, and MUC19. Thus, C8-2 contains an odd number of Cys residues (i.e., 9), so that one can expect that this domain is capable of forming an inter-molecular disulfide bridge at $\mathrm{Cys}^{587}$ characteristic of MUC6 (Fig. 3). Furthermore, Cys ${ }^{1100}$ in C8-3 of MUC6 corresponds to the homologous Cys ${ }^{1099}$ of vWF, which forms a homophilic inter-molecular disulfide bridge essential for assembly of vWF (99). However, C8-3 in MUC6 (and also MUC2, MUC5AC, MUC5B, and MUC19) contains an additional $\mathrm{Cys}$ residue $\left(\mathrm{Cys}^{1118}\right)$ when compared with vWF resulting in an even number (i.e., 12). Thus, one could conclude, that the C8-3 MUC6 is capable of forming either two (if $\mathrm{Cys}^{1100}$ forms an inter-molecular disulfide bridge) or no inter-molecular disulfide bridge (if $\mathrm{Cys}^{1100}$ does not form an inter-chain bridge). Additionally, the TIL-3 domain is somewhat changed in MUC6. However, Cys ${ }^{1153}$ of MUC6 is homologous to Cys ${ }^{1142}$ in vWF, Cys ${ }^{1130}$ in MUC2, and Cys ${ }^{1199}$ in porcine submaxillary mucin (PSM)/Muc19; the latter three cysteine residues have been shown to form a homophilic 


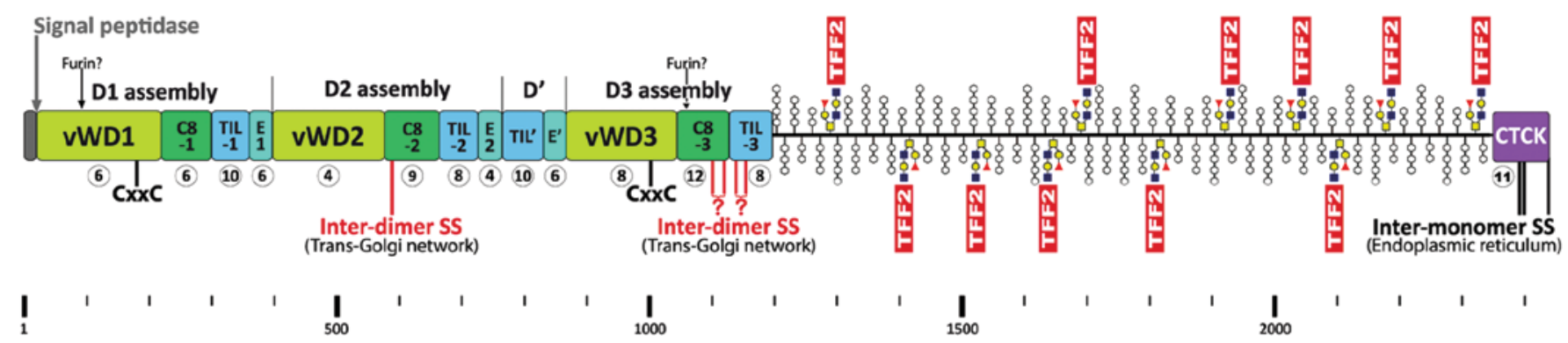

Figure 3. Schematic representation of the human mucin MUC6 and its interactions with TFF2. The mosaic domain structure of MUC6 (cysteine-rich N-terminal D1D2D'D3 and C-terminal CTCK domains) is depicted by its striking similarity to human von Willebrand factor (vWF) (100). Domains are scaled to length and residues are shown with pre-pro numbering. The number of cysteine residues in each domain is indicated (encircled). Also shown are the predicted inter-molecular disulfide bridges involved in C-terminal dimerization (inter-monomer SS, black) and N-to-N multimerization (inter-dimer SS, red) as well as the $\mathrm{CxxC}$ disulfide isomerase motifs and potential furin cleavage sites. The oligosaccharides in the central highly O-glycosylated PTS domain are indicated by multiple hexagons, whereas the structure GlcNAc $\alpha 1-4 G a 1 \beta 1-4 G 1 c N A c \beta 1-6($ Fuc $\alpha 1-2 G a 1 \beta 1-3) G a l N A c$ is shown coloured. The non-covalent lectin binding of TFF2 (containing two TFF domains) to GlcNAc $\alpha 1-4 \mathrm{Gal} \beta 1-4 \mathrm{GlcNAc} \beta$ (88) would be perfectly designed to crosslink MUC6-monomers as well as MUC6-dimers. Furthermore, TFF2 could also covalently crosslink MUC6-dimers by forming heterophilic disulfide bridges between cysteine residues involved in N-to-N multimerization (red).

inter-molecular disulfide bridge essential for assembly of vWF (99), MUC2 (102), and PSM/Muc19 (103), respectively. Because TIL-3 in MUC6 contains an even number (i.e., 8) of Cys residues it is not clear if TIL-3 is capable of forming inter-molecular disulfide bridges in MUC6 (similar situation as in C8-3). Taken together, Cys ${ }^{587}$ in C8-2 of MUC6 (Fig. 3) is a prime candidate for an inter-chain disulfide bridge, either homophilic or heterophilic with TFF2 as a cross-linker (Fig. 3). Further potential inter-molecular disulfide bridges could originate from C8-3 and TIL-3 (either homophilic or heterophilic with TFF2; Fig. 3).

The C-terminal cysteine-rich domain of MUC6 is much shorter than that of the other secretory mucins and vWF (104) and it has been shown to be responsible for dimerization (98). It consists only of a CTCK domain containing an odd number of Cys residues (i.e., 11) with striking similarity to vWF (105). It is known that three intra-chain disulfide bridges of the CTCK domain are responsible for C-to-C dimerization of vWF in the endoplasmic reticulum (106). A similar situation has been reported for PSM/Muc19 (107). Thus, it is expected that the homologous residues (i.e., $\mathrm{Cys}^{2393}, \mathrm{Cys}^{2395}$, and $\mathrm{Cys}^{2437}$ ) in MUC6 are also involved in dimerization of MUC6 (Fig. 3). Whether cross-linking via TFF2 plays a role in this process is a matter of speculation.

Function of TFF2 for MUC6 assembly in the secretory pathway and for mucus rheology. Based on multiple and characteristic structural similarities, the biosynthesis of MUC6 is generally expected to share many typical features already observed in both vWF (100) and secretory mucins $(2,96,108)$. Furthermore, TFF2 and MUC6 are co-expressed in the same cells, and it is expected that TFF2 and MUC6 share the same secretory pathway and end up in the same secretory vesicles.

The primary translation product of MUC6 is probably co-translationally cleaved by the signal peptidase and then dimerizes in the endoplasmic reticulum (ER; $\mathrm{pH} \sim 7.5$ ) via disulfide bridges in the CTCK domain (Fig. 3) similar to vWF $(100,106)$ as well as MUC2 and other gel-forming mucins $(96,98)$. Generally, folding and initial polymerization of mucins occur in the ER, which requires the protein disulfide isomerase

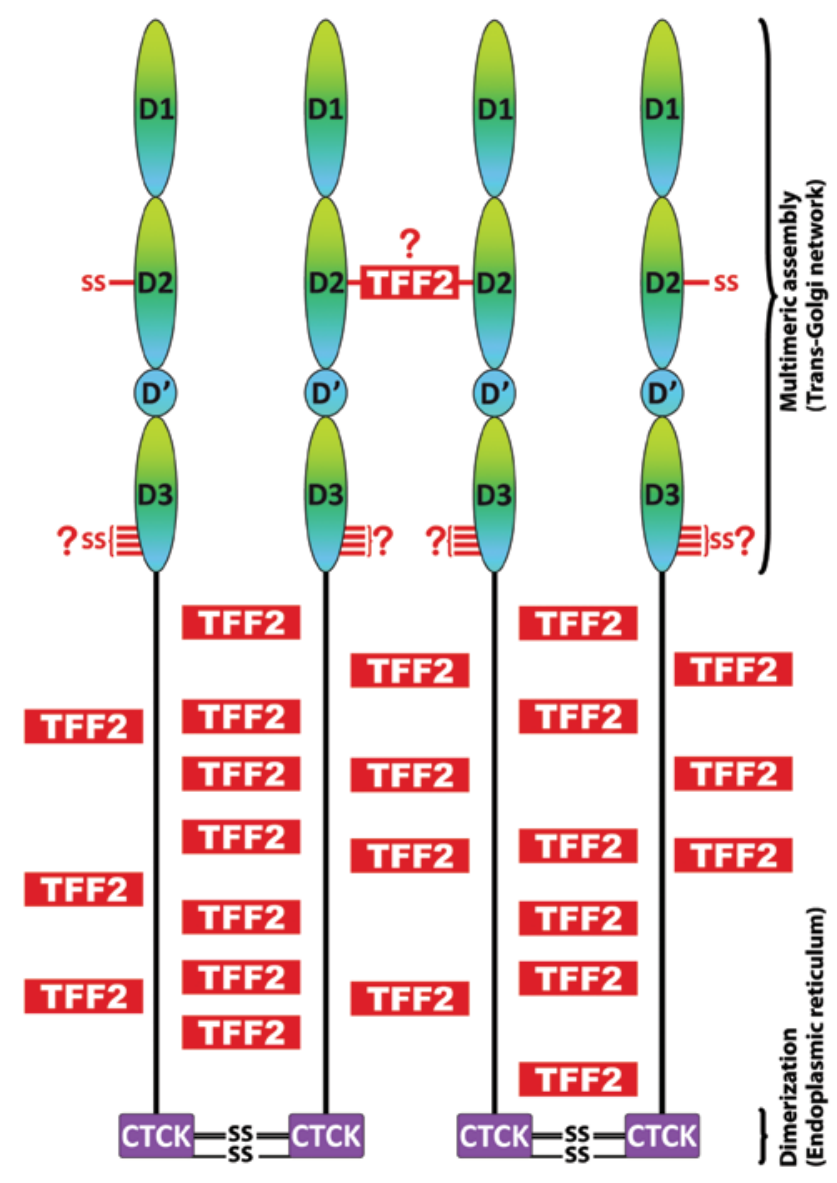

Figure 4. Suggested structure of the condensed and highly organized form of the MUC6/TFF2 complex in the secretory granules. On the one hand, non-covalent lectin interactions of MUC6 (via its PTS domain) and TFF2 are expected to result in dimeric bouquet structures, which could even show supra-structural organization. On the other hand, besides $\mathrm{C}$-to-C dimerization, $\mathrm{N}$-to-N multimeric assembly is expected to occur via the D2 (C8-2; see Fig. 3) and maybe also the D3 domains (C8-3 and TIL-3; see Fig. 3) probably resulting in a branched structure. Here, TFF2 could also covalently crosslink MUC6dimers by forming heterophilic disulfide bridges.

AGR2 (109,110). AGR2 has been reported to be involved in ER stress and the unfolded protein response (111). Of note, AGR2 
is expressed in the stomach specifically together with MUC6 and TFF2 in mucous neck and antral gland cells, respectively and $\mathrm{Agr} 2^{\mathrm{KO}}$ mice develop severe glandular hyperplasia at the expense of chief but also of pit and parietal cells (112). If the protein disulfide isomerase ERp57 and the calnexincalreticulin cycle play a role for correct folding of MUC6 and/ or TFF2 is not known currently.

As the next steps in the secretory pathway, $\mathrm{N}$ - and O-glycosylations of MUC6 are completed in the Golgi and multimerization via the N-terminal D1D2D'D3 domain occurs in the trans-Golgi network ( $\mathrm{pH} \sim 6.0$ ). Multimerization of both vWF as well as the mucins MUC2 and PSM/Muc19 is known to require an acidic $\mathrm{pH}$ and $\mathrm{Ca}^{2+}$ as well as an intrinsic oxidoreductase activity (CxxC motifs) (103,113-115). Thus, the CxxC motifs in the vWD1 and vWD3 domains (Fig. 3) are expected to catalyze N-to-N multimerization of MUC6. However, multimerization of $\mathrm{vWF}$ occurs via N-terminal dimerization $(100,114)$, whereas both MUC2 and PSM/Muc19 form $\mathrm{N}$-terminal trimers $(96,102,116)$. This fundamental difference in the multimerization between vWF and MUC2 leads to linear thread-like structures in vWF and two-dimensional net-like sheets in MUC2, respectively. It is not known currently, how MUC6 multimerizes. Of special note, the N-terminal assembly domain of human MUC6 differs characteristically by some cysteine residues when compared with conserved positions in both vWF and the secretory mucins MUC2, MUC5AC, MUC5B (Fig. 3): particularly $\mathrm{Cys}^{587}(\mathrm{C} 8-2)$ is present in MUC6 only, whereas some conserved cysteine residues in the C8-1 and vWD2 domains are lacking in MUC6. The latter also lacks the E3 and CysD domains and C-terminal cysteine-rich regions (96). Furthermore, in contrast to the human secretory mucins MUC2, MUC5AC, MUC5B, and MUC19, His ${ }^{395}$ essential for $\mathrm{pH}$-dependent multimerization of $\mathrm{vWF}(117)$ is not conserved in MUC6. On the other hand, TFF2 is synthesized together with MUC6 connecting the PTS domains via its lectin activity (Fig. 3) and probably also forming disulfide bridge(s) with MUC6, e.g., at $\mathrm{Cys}^{587}$ (perhaps with the help of the CxxC motifs in vWD1 and vWD3; Fig. 3). Non-covalent cross-linking of the PTS domains via TFF2 could play a major role for zipping up a dimeric MUC6 bouquet (Fig. 4), a reaction with functional analogy to vWF (100). Taken together, the multimerization of MUC6 is expected to be different from both vWF and the mucins MUC2 and PSM/Muc19; for MUC6, a complex branched rather than a simple linear structure is expected. TFF2 probably plays a role here.

It should be mentioned that MUC6 as well as the secretory mucins MUC2, MUC5AC, and MUC5B contain 2 potential furin cleavage sites at conserved positions (in MUC6 after positions 88 and 1054, respectively; Fig. 3). It is not known currently whether MUC6 is processed by this $\mathrm{Ca}^{2+}$-dependent protease.

The last steps in the secretory pathway of MUC6/TFF2 are storage in secretory granules (diameter of mucin granules: $<1 \mu \mathrm{m})$ and mainly regulated exocytosis after extracellular stimulation with a secretagogue, such as ATP (110). Secretory granules from a variety of cells are typical acidic $\mathrm{Ca}^{2+}$ stores ( $\mathrm{pH}$ 5.5-5.9; total $\mathrm{Ca}^{2+}$ bound to a matrix, 20-150 mM; free $\left.\mathrm{Ca}^{2+}, 10-100 \mu \mathrm{M}\right)(118,119)$. In contrast, resting $\mathrm{Ca}^{2+}$ levels in the cytosol are only $\sim 100 \mathrm{nM}$. Progressive acidification along the secretory pathway is maintained by a vesicular $\mathrm{H}^{+}$-ATPase and $\mathrm{Ca}^{2+}$ uptake probably occurs via a SERCA-type $\mathrm{Ca}^{2+}$ ATPase $(119,120)$. Furthermore, there are probably also channels for $\mathrm{K}^{+}$and $\mathrm{Cl}^{-}$import; whereas $\mathrm{Ca}^{2+}$ release is probably operated by IP3/ryanodine receptors $(118,120)$. It has been demonstrated that both vWF as well as secretory mucins are stored in a highly condensed and well-organized packaging in the corresponding secretory granules in the presence of $\mathrm{Ca}^{2+}$ at $\mathrm{pH}<6.0$. vWF assembles into helices forming the tubules of the Weibel-Palade bodies $(100,114)$; whereas secretory mucins are tightly packed forming a condensed polyanionic matrix with $\mathrm{Ca}^{2+}$ as counter-ions embedded in a fluid phase $(108,115,121,122)$. Particular for MUC2 a detailed mechanistic model has been proposed for packaging and unfolding (115). In the case of MUC6, non-covalent cross-linking of the PTS domains via the lectin activity of TFF2 would be a perfect design enforcing extremely dense packaging of MUC6 within the secretory granules (Fig. 4). Furthermore, the many acidic residues of TFF2, often clustered, could also serve as additional $\mathrm{Ca}^{2+}$ binding sites. During exocytosis, rapid unfolding of condensed mucins is triggered by an exchange of $\mathrm{Ca}^{2+}$ against $\mathrm{Na}^{+}$from the extracellular fluid thus doubling the number of counter-ions and causing the mucin polymer to expand up to 600 -fold in its volume by osmotic swelling within $20-30 \mathrm{msec}$ $(108,122,123,124)$. Of special note, $\mathrm{HCO}_{3}{ }^{-}$plays a crucial role for the extremely rapid transition into the expanded hydrated phase because it efficiently competes for $\mathrm{Ca}^{2+}$ binding (125). In many organs, this process is linked with the CFTR-channel, which also transports $\mathrm{HCO}_{3}{ }^{-}$. However, in the human stomach the CFTR is expressed at low levels only and gastric surface epithelial cells secrete abundantly bicarbonate via an apical $\mathrm{Cl}^{-} / \mathrm{HCO}_{3}{ }^{-}$exchanger (50) allowing expansion of MUC6. Gastric $\mathrm{HCO}_{3}^{-}$secretion is stimulated by E-type prostaglandins (50), which is in agreement with their general protective function - here, in particular due to their role for proper MUC6 exocytosis.

Upon release and expansion of MUC6, TFF2 still stays attached also at lower $\mathrm{Ca}^{2+}$ concentrations allowing the formation of three-dimensional networks. Generally, the assembly and the structure of the TFF2-MUC6 network are expected to be quite different when compared with MUC2. TFF2 seems to be an important link peptide enabling a dense MUC6 network, which is typical of glands (fundic glands, antral glands, Brunner's glands). This would also explain why native MUC6 appeared to be of larger size than MUC5AC $(12,52)$ despite the fact that the MUC6 monomer is much smaller than that of MUC5AC. The formation of large TFF2-MUC6 complexes probably supports the proper excretory flow from the gastric glands (54). Furthermore, the large TFF2-MUC6 complexes probably ensure that MUC5AC and MUC6 do not mix homogeneously, but rather form a layered mucus structure.

The proposed role of TFF2 for MUC6 assembly and rheology fits well with several experimental observations. For example, TFF2 increased dramatically the viscosity and elasticity of porcine gastric mucin solutions in vitro (126). These solutions showed non-Newtonian pseudo-plastic behavior, i.e., the viscosity decreased when increasing the applied shear rate (126). Such a behavior is typical of an entangled network. Of note, the viscous response was $\mathrm{pH}$-dependent with highest viscosity at low $\mathrm{pH}$ (126). This is typical of gastric mucus (127) and is an indication for the involvement of hydrogen bonds. 
Furthermore, systemically administered TFF2 in vivo also increased the viscosity of stomach secretions after uptake and probably transcytosis to the mucosal surface (128). Also the effects on gastric $\mathrm{pH}$ regulation (45) and proton permeation through gastric mucus (129) fit well with a role of TFF2 for MUC6 assembly and stabilization of the mucus barrier.

TFF 2 orthologs in the amphibian gastrointestinal tract. In the Xenopus laevis stomach epithelium, two peptides consisting of four TFF modules arranged in tandem are expressed in mucous neck and antral gland cells (xP4.1 and xP4.2) (130). They are considered to be the $X$. laevis functional homologs of mammalian TFF2 (31). Interestingly, xP4.1 is N-glycosylated (as is human TFF2) and expressed in all regions of the stomach; whereas xP4.2 lacks the N-glycosylation site (131) and is expressed with a decreasing gradient from the fundus to the antrum (31). Thus far, it is not known if xP4.1 contains the LacdiNAc oligosaccharide as human TFF2. However, both xP4.1 and xP4.2 contain $4 \times 6$ cysteine residues typical of the four TFF domains and, in contrast to TFF2, lack the additional cysteine residues at the $\mathrm{N}$ - and $\mathrm{C}$-termini typical of TFF2 (Fig. 1). Thus, there is no additional disulfide bridge in xP4 equivalent to $\mathrm{Cys}^{6}-\mathrm{Cys}^{104}$ of TFF2 (Fig. 1), which could be opened and used for a covalent cross-linking of a MUC6 homolog. As a consequence, the xP4 peptides are expected to only bind non-covalently via a lectin activity to the mucin.

\section{Conclusions and future perspectives}

TFF2 and the gastric barrier. Cross-linking of mucins, by both covalent and non-covalent interactions, plays a key role for the assembly of the laminated structure and the rheological properties of gastric mucus. Sugar-lectin interactions are known to stabilize mucin films in order to sustain their exceptional resistance to extreme salt conditions and to a broad $\mathrm{pH}$ range (132). The latter is particularly important for the gastric mucus, where the secreted hydrochloric acid is transported through temporary canals (86) and zymogenic secretions form initially droplet-like structures which finally merge with the gland mucus (54). Thus, TFF2 is expected to play a major role for cross-linking MUC6 and stabilizing particularly the mucus barrier of gastric glands as a 'link peptide'. However, many details still await experimental elucidation, particularly the N-to-N assembly of MUC6. Unfortunately, the data basis describing this process (98) is by far not comparable with that for MUC2, PSM/Muc19 or vWF.

As gastric mucus regulates the colonization with $H$. pylori (61), it is not to surprising that TFF2 is probably also involved in this process (25). TFF2 also has a protective function against the progression of premalignant lesions in $\mathrm{H}$. pyloriinfected mice (44). This is in line with the observation that epigenetic silencing of TFF2 by $H$. pylori infection leads to gastric tumor development (133). The human stomach is also the host for a variety of non- $H$. pylori microbiota (134) and it will be interesting in the future to determine whether TFF2 plays a role in the colonization of these microorganisms.

More roles for TFF 2 and TFF modules as lectins in mucous epithelia, the immune system, the CNS, and during fertilization. TFF2 is also ectopically secreted from a variety of mucous epithelia during stone diseases, such as nephrolithiasis, hepatolithiasis, dacryolithiasis, and cholecystolithiasis $(135,136)$. Thus, TFF2, together with MUC6, would be a prime candidate for initiating the complex process of stone formation. Furthermore, $\mathrm{pH}$-dependent lectin activities have also been reported for TFF1 and TFF3 (137). Thus far, the carbohydrate specificities of TFF1 and TFF3 have not been determined. However, there are indications that the binding characteristics of these peptides are different. A general lectin activity of TFF domains could functionally explain the occurrence of such modules in various mosaic proteins, such as certain zona pellucida proteins (ZP1, ZPB), intestinal sugar-degrading enzymes (sucrase-isomaltase, $\alpha$-glucosidase, maltase-glucoamylase), and some frog integumentary mucins (FIM-A.1, FIM-C.1) (compilations in refs. 31,138). Clearly, a function for the 3D-structure and rheology of mucus can easily be inferred for the TFF domains in frog integumentary mucins. However, a molecular function of TFF domains also beyond the structure of mucus and stone formation can be expected, e.g., during fertilization or for the extracellular degradation of saccharides. Interestingly, all TFF domains analyzed thus far are encoded by single exons establishing this domain as an evolutionary conserved shuffled lectin module.

Furthermore, the lectin activity could also explain the multiple and diverse biological effects of TFF2 [e.g., motogenic, proliferative, (anti)apoptotic, and angiogenic effects] (reviewed in refs. $4,5,31,41,104$ ) by binding to a plethora of transmembrane glycoproteins, such as receptors, e.g., CXCR4 (40,41), integrins (42), and a CRP-Ductin/DMBT1/gp-340-like glycoprotein (42). Such transmembrane glycoproteins interacting with TFF2 (and possibly also with TFF1 and TFF3) are expected to occur particularly in the immune and central nervous systems, e.g., the body weight is regulated by hypothalamic TFF2 (139). In particular, the relatively high dissociation constants of lectin interactions explain now conclusively why relatively high TFF2 concentrations were necessary for biological activity $(40,41)$. Furthermore, similar to galectins $(140,141)$, TFF2 is also perfectly designed to form various two- and three-dimensional cross-linked lattices with transmembrane glycoproteins at the cell surface. Thus, TFF2, and probably also TFF1 and TFF3, are reminiscent to galectins in some ways, both occurring in the digestive tract as well as the immune and the nervous systems and regulating a variety of different biological processes not related to mucus.

\section{Acknowledgements}

The author would like to thank D. Lorenz for excellent secretarial assistance, F. Richter for help in computer searches, and Dr J. Lindquist for critically reading the manuscript.

\section{References}

1. Laine L, Takeuchi K and Tarnawski A: Gastric mucosal defense and cytoprotection: Bench to bedside. Gastroenterology 135: 41-60, 2008.

2. Thornton DJ, Rousseau K and McGuckin MA: Structure and function of the polymeric mucins in airways mucus. Annu Rev Physiol 70: 459-486, 2008.

3. Senapati S, Sharma P, Bafna S, Roy HK and Batra SK: The MUC gene family: Their role in the diagnosis and prognosis of gastric cancer. Histol Histopathol 23: 1541-1552, 2008. 
4. Kjellev S: The trefoil factor family - small peptides with multiple functionalities. Cell Mol Life Sci 66: 1350-1369, 2009.

5. Hoffmann W: TFF peptides. In: Handbook of Biologically Active Peptides. 2nd edition. Kastin A (ed). Elsevier, San Diego, pp1338-1345, 2013.

6. Thim L: Trefoil peptides: From structure to function. Cell Mol Life Sci 53: 888-903, 1997.

7. Wright NA, Hoffmann W, Otto WR, Rio MC and Thim L: Rolling in the clover: Trefoil factor family (TFF)-domain peptides, cell migration and cancer. FEBS Lett 408: 121-123, 1997.

8. Thim L: A new family of growth factor-like peptides. 'Trefoil' disulphide loop structures as a common feature in breast cancer associated peptide ( $\mathrm{pS} 2)$, pancreatic spasmolytic polypeptide (PSP), and frog skin peptides (spasmolysins). FEBS Lett 250: 85-90, 1989.

9. Gajhede M, Petersen TN, Henriksen A, Petersen JFW, Dauter Z, Wilson KS and Thim L: Pancreatic spasmolytic polypeptide: First three-dimensional structure of a member of the mammalian trefoil family of peptides. Structure 1: 253-262, 1993.

10. Hanisch FG, Ragge H, Kalinski T, Meyer F, Kalbacher H and Hoffmann W: Human gastric TFF2 peptide contains an N-linked fucosylated N,N'-diacetyllactosediamine (LacdiNAc) oligosaccharide. Glycobiology 23: 2-11, 2013.

11. Petersen TN, Henriksen A and Gajhede M: Structure of porcine pancreatic spasmolytic polypeptide at 1.95 A resolution. Acta Crystallogr D Biol Crystallogr 52: 730-737, 1996.

12. Stürmer R, Müller S, Hanisch FG and Hoffmann W: Porcine gastric TFF2 is a mucus constituent and differs from pancreatic TFF2. Cell Physiol Biochem 33: 895-904, 2014.

13. Tomasetto C, Rio MC, Gautier C, Wolf C, Hareuveni M, Chambon P and Lathe R: hSP, the domain-duplicated homolog of $\mathrm{pS} 2$ protein, is co-expressed with $\mathrm{pS} 2$ in stomach but not in breast carcinoma. EMBO J 9: 407-414, 1990.

14. Rasmussen TN, Raaberg L, Poulsen SS, Thim L and Holst JJ: Immunohistochemical localization of pancreatic spasmolytic polypeptide (PSP) in the pig. Histochemistry 98: 113-119, 1992.

15. Hanby AM, Poulsom R, Singh S, Elia G, Jeffery RE and Wright NA: Spasmolytic polypeptide is a major antral peptide: Distribution of the trefoil peptides human spasmolytic polypeptide and pS2 in the stomach. Gastroenterology 105: 1110-1116, 1993.

16. Hanby AM, Poulsom R, Elia G, Singh S, Longcroft JM and Wright NA: The expression of the trefoil peptides pS2 and human spasmolytic polypeptide (hSP) in 'gastric metaplasia' of the proximal duodenum: Implications for the nature of 'gastric metaplasia'. J Pathol 169: 355-360, 1993.

17. Poulsom R: Trefoil peptides. Baillieres Clin Gastroenterol 10 : 113-134, 1996.

18. Ota H, Hayama M, Momose M, El-Zimaity HMT, Matsuda K, Sano K, Maruta F, Okumura N and Katsuyama T: Co-localization of TFF2 with gland mucous cell mucin in gastric mucous cells and in extracellular mucous gel adherent to normal and damaged gastric mucosa. Histochem Cell Biol 126: 617-625, 2006.

19. Kouznetsova I, Kalinski T, Meyer F and Hoffmann W: Selfrenewal of the human gastric epithelium: New insights from expression profiling using laser microdissection. Mol Biosyst 7: 1105-1112, 2011.

20. Quante M, Marrache F, Goldenring JR and Wang TC: TFF2 mRNA transcript expression marks a gland progenitor cell of the gastric oxyntic mucosa. Gastroenterology 139: 2018-2027.e2012, 2010.

21. Jeffrey GP, Oates PS, Wang TC, Babyatsky MW and Brand SJ: Spasmolytic polypeptide: A trefoil peptide secreted by rat gastric mucous cells. Gastroenterology 106: 336-345, 1994.

22. Semple JI, Newton JL, Westley BR and May FE: Dramatic diurnal variation in the concentration of the human trefoil peptide TFF2 in gastric juice. Gut 48: 648-655, 2001.

23. Kouznetsova I, Gerlach KL, Zahl C and Hoffmann W: Expression analysis of human salivary glands by laser microdissection: Differences between submandibular and labial glands. Cell Physiol Biochem 26: 375-382, 2010

24. Cook GA, Familari M, Thim L and Giraud AS: The trefoil peptides TFF2 and TFF3 are expressed in rat lymphoid tissues and participate in the immune response. FEBS Lett 456: 155-159, 1999.

25. Kurt-Jones EA, Cao L, Sandor F, Rogers AB, Whary MT Nambiar PR, Cerny A, Bowen G, Yan J, Takaishi S, et al: Trefoil family factor 2 is expressed in murine gastric and immune cells and controls both gastrointestinal inflammation and systemic immune responses. Infect Immun 75: 471-480, 2007.
26. Hinz M, Schwegler H, Chwieralski CE, Laube G, Linke R, Pohle W and Hoffmann W: Trefoil factor family (TFF) expression in the mouse brain and pituitary: Changes in the developing cerebellum. Peptides 25: 827-832, 2004.

27. Wong WM, Playford RJ and Wright NA: Peptide gene expression in gastrointestinal mucosal ulceration: Ordered sequence or redundancy? Gut 46: 286-292, 2000.

28. Poulsom R and Wright NA: Trefoil peptides: A newly recognized family of epithelial mucin-associated molecules. Am J Physiol 265: G205-G213, 1993.

29. Wright NA: Aspects of the biology of regeneration and repair in the human gastrointestinal tract. Philos Trans R Soc Lond B Biol Sci 353: 925-933, 1998.

30. Longman RJ, Thomas MG and Poulsom R: Trefoil peptides and surgical disease. Br J Surg 86: 740-748, 1999.

31. Hoffmann W and Jagla W: Cell type specific expression of secretory TFF peptides: Colocalization with mucins and synthesis in the brain. Int Rev Cytol 213: 147-181, 2002.

32. Schmidt PH, Lee JR, Joshi V, Playford RJ, Poulsom R, Wright NA and Goldenring JR: Identification of a metaplastic cell lineage associated with human gastric adenocarcinoma. Lab Invest 79: 639-646, 1999.

33. Nam KT, Lee HJ, Sousa JF, Weis VG, O'Neal RL, Finke PE, Romero-Gallo J, Shi G, Mills JC, Peek RM Jr, et al: Mature chief cells are cryptic progenitors for metaplasia in the stomach. Gastroenterology 139: 2028-2037.e9, 2010.

34. Goldenring JR, Nam KT, Wang TC, Mills JC and Wright NA: Spasmolytic polypeptide-expressing metaplasia and intestinal metaplasia: time for reevaluation of metaplasias and the origins of gastric cancer. Gastroenterology 138: 2207-2210, 2210.e2201, 2010

35. Playford RJ: Peptides and gastrointestinal mucosal integrity. Gut 37: 595-597, 1995.

36. Poulsen SS, Kissow H, Hare K, Hartmann B and Thim L: Luminal and parenteral TFF2 and TFF3 dimer and monomer in two models of experimental colitis in the rat. Regul Pept 126: 163-171, 2005.

37. Vandenbroucke K, Hans W, Van Huysse J, Neirynck S, Demetter P, Remaut E, Rottiers P and Steidler L: Active delivery of trefoil factors by genetically modified Lactococcus lactis prevents and heals acute colitis in mice. Gastroenterology 127: 502-513, 2004.

38. Graness A, Chwieralski CE, Reinhold D, Thim L and Hoffmann W: Protein kinase $C$ and ERK activation are required for TFF-peptide-stimulated bronchial epithelial cell migration and tumor necrosis factor- $\alpha$-induced interleukin- 6 (IL-6) and IL-8 secretion. J Biol Chem 277: 18440-18446, 2002.

39. Chwieralski CE, Schnurra I, Thim L and Hoffmann W: Epidermal growth factor and trefoil factor family 2 synergistically trigger chemotaxis on BEAS-2B cells via different signaling cascades. Am J Respir Cell Mol Biol 31: 528-537, 2004

40. Dubeykovskaya Z, Dubeykovskiy A, Solal-Cohen J and Wang TC: Secreted trefoil factor 2 activates the CXCR4 receptor in epithelial and lymphocytic cancer cell lines. J Biol Chem 284: 3650-3662, 2009

41. Hoffmann W: Trefoil factor family (TFF) peptides and chemokine receptors: A promising relationship. J Med Chem 52: 6505-6510, 2009

42. Thim L and Mørtz E: Isolation and characterization of putative trefoil peptide receptors. Regul Pept 90: 61-68, 2000.

43. Poulsen SS, Thulesen J, Nexø E and Thim L: Distribution and metabolism of intravenously administered trefoil factor $2 /$ porcine spasmolytic polypeptide in the rat. Gut 43: 240-247, 1998 .

44. Fox JG, Rogers AB, Whary MT, Ge Z, Ohtani M, Jones EK and Wang TC: Accelerated progression of gastritis to dysplasia in the pyloric antrum of TFF2 $2^{-1}$ C57BL6 $x$ Sv129 Helicobacter pyloriinfected mice. Am J Pathol 171: 1520-1528, 2007.

45. Xue L, Aihara E, Podolsky DK, Wang TC and Montrose MH: In vivo action of trefoil factor 2 (TFF2) to speed gastric repair is independent of cyclooxygenase. Gut 59: 1184-1191, 2010.

46. Baus-Loncar M, Schmid J, Lalani N, Rosewell I, Goodlad RA, Stamp GWH, Blin N and Kayademir T: Trefoil factor 2 (TFF2) deficiency in murine digestive tract influences the immune system. Cell Physiol Biochem 16: 31-42, 2005.

47. Shah AA, Mihalj M, Ratkay I, Lubka-Pathak M, Balogh P, Klingel K, Bohn E, Blin N and Baus-Loncar M: Increased susceptibility to Yersinia enterocolitica infection of Tff 2 deficient mice. Cell Physiol Biochem 30: 853-862, 2012.

48. McBerry C, Egan CE, Rani R, Yang Y, Wu D, Boespflug N, Boon L, Butcher B, Mirpuri J, Hogan SP, et al: Trefoil factor 2 negatively regulates type 1 immunity against Toxoplasma gondii. J Immunol 189: 3078-3084, 2012. 
49. Allen A: Gastrointestinal mucus. Section 6: The gastrointestinal system. In: Handbook of physiology. Vol. III. Schultz SG (ed.) Am Physiol Soc., Bethesda, MD, pp359-382, 1989.

50. Allen A and Flemström G: Gastroduodenal mucus bicarbonate barrier: Protection against acid and pepsin. Am J Physiol Cell Physiol 288: C1-C19, 2005.

51. De Bolós C, Garrido M and Real FX: MUC6 apomucin shows a distinct normal tissue distribution that correlates with Lewis antigen expression in the human stomach. Gastroenterology 109: 723-734, 1995.

52. Nordman H, Davies JR, Lindell G, de Bolós C, Real F and Carlstedt I: Gastric MUC5AC and MUC6 are large oligomeric mucins that differ in size, glycosylation and tissue distribution. Biochem J 364: 191-200, 2002

53. Hoffmann W: Self-renewal of the gastric epithelium from stem and progenitor cells. Front Biosci (Schol Ed) 5: 720-731, 2013.

54. Sawaguchi A, Ishihara K, Kawano Ji J, Oinuma T, Hotta K and Suganuma T: Fluid dynamics of the excretory flow of zymogenic and mucin contents in rat gastric gland processed by highpressure freezing/freeze substitution. J Histochem Cytochem 50: 223-234, 2002

55. Byrd JC, Yan P, Sternberg L, Yunker CK, Scheiman JM and Bresalier RS: Aberrant expression of gland-type gastric mucin in the surface epithelium of Helicobacter pylori-infected patients. Gastroenterology 113: 455-464, 1997.

56. Ishihara K, Kurihara M, Goso Y, Urata T, Ota H, Katsuyama T and Hotta K: Peripheral $\alpha$-linked N-acetylglucosamine on the carbohydrate moiety of mucin derived from mammalian gastric gland mucous cells: Epitope recognized by a newly characterized monoclonal antibody. Biochem J 318: 409-416, 1996.

57. Nakayama J, Yeh JC, Misra AK, Ito S, Katsuyama T and Fukuda M: Expression cloning of a human $\alpha 1,4-\mathrm{N}$-acetylglucosaminyltransferase that forms GlcNA $\alpha 1 \rightarrow 4 \mathrm{Gal} \beta \rightarrow \mathrm{R}$, a glycan specifically expressed in the gastric gland mucous cell-type mucin. Proc Natl Acad Sci USA 96: 8991-8996, 1999.

58. Karasawa F, Shiota A, Goso Y, Kobayashi M, Sato Y, Masumoto J, Fujiwara M, Yokosawa S, Muraki T, Miyagawa S, et al: Essential role of gastric gland mucin in preventing gastric cancer in mice. J Clin Invest 122: 923-934, 2012

59. Yang DH, Tsuyama S, Hotta K, Katsuyama $T$ and Murata $F$ : Expression of $\mathrm{N}$-acetylglucosamine residues in developing rat fundic gland cells. Histochem J 32: 187-193, 2000.

60. Nakayama J, Katsuyama T and Fukuda M: Recent progress in paradoxical concanavalin A staining. Acta Histochem Cytochem 33: $153-157,2000$.

61. Skoog EC, Sjöling Å, Navabi N, Holgersson J, Lundin SB and Lindén SK: Human gastric mucins differently regulate Helicobacter pylori proliferation, gene expression and interactions with host cells. PLoS One 7: e36378, 2012

62. Shimizu T, Akamatsu T, Sugiyama A, Ota $\mathrm{H}$ and Katsuyama T: Helicobacter pylori and the surface mucous gel layer of the human stomach. Helicobacter 1: 207-218, 1996.

63. Van den Brink GR, Tytgat KM, Van der Hulst RW, Van der Loos CM, Einerhand AWC, Büller HA and Dekker J: H. pylori colocalises with MUC5AC in the human stomach. Gut 46 601-607, 2000

64. Hidaka E, Ota H, Hidaka H, Hayama M, Matsuzawa K, Akamatsu T, Nakayama J and Katsuyama T: Helicobacter pylori and two ultrastructurally distinct layers of gastric mucous cell mucins in the surface mucous gel layer. Gut 49: 474-480, 2001

65. Kawakubo M, Ito Y, Okimura Y, Kobayashi M, Sakura K, Kasama S, Fukuda MN, Fukuda M, Katsuyama T and Nakayama J: Natural antibiotic function of a human gastric mucin against Helicobacter pylori infection. Science 305 : 1003-1006, 2004.

66. Jonckheere $\mathrm{N}$ and Van Seuningen I: The membrane-bound mucins: From cell signalling to transcriptional regulation and expression in epithelial cancers. Biochimie 92: 1-11,2010.

67. McGuckin MA, Lindén SK, Sutton P and Florin TH: Mucin dynamics and enteric pathogens. Nat Rev Microbiol 9: 265-278, 2011.

68. Phillipson M, Johansson ME, Henriksnäs J, Petersson J, Gendler SJ, Sandler S, Persson AEG, Hansson GC and Holm L: The gastric mucus layers: Constituents and regulation of accumulation. Am J Physiol Gastrointest Liver Physiol 295: G806-G812, 2008.

69. Williams SJ, Wreschner DH, Tran M, Eyre HJ, Sutherland GR and McGuckin MA: Muc13, a novel human cell surface mucin expressed by epithelial and hemopoietic cells. J Biol Chem 276: $18327-18336,2001$.
70. Menheniott TR, Kurklu B and Giraud AS: Gastrokines: Stomachspecific proteins with putative homeostatic and tumor suppressor roles. Am J Physiol Gastrointest Liver Physiol 304: G109-G121, 2013.

71. Kang W, Nielsen O, Fenger C, Madsen J, Hansen S, Tornoe I, Eggleton P, Reid KBM and Holmskov U: The scavenger receptor, cysteine-rich domain-containing molecule gp-340 is differentially regulated in epithelial cell lines by phorbol ester. Clin Exp Immunol 130: 449-458, 2002.

72. Nio-Kobayashi J, Takahashi-Iwanaga $\mathrm{H}$ and Iwanaga T: Immunohistochemical localization of six galectin subtypes in the mouse digestive tract. J Histochem Cytochem 57: 41-50, 2009.

73. O'Neil DA, Cole SP, Martin-Porter E, Housley MP, Liu L, Ganz T and Kagnoff MF: Regulation of human $\beta$-defensins by gastric epithelial cells in response to infection with Helicobacter pylori or stimulation with interleukin-1. Infect Immun 68: 5412-5415, 2000.

74. Hase K, Murakami M, Iimura M, Cole SP, Horibe Y, Ohtake T, Obonyo M, Gallo RL, Eckmann L and Kagnoff MF: Expression of LL-37 by human gastric epithelial cells as a potential host defense mechanism against Helicobacter pylori. Gastroenterology 125 1613-1625, 2003.

75. Aloulou A and Carrière F: Gastric lipase: An extremophilic interfacial enzyme with medical applications. Cell Mol Life Sci 65: 851-854, 2008.

76. Mauch F, Bode G, Ditschuneit H and Malfertheiner P Demonstration of a phospholipid-rich zone in the human gastric epithelium damaged by Helicobacter pylori. Gastroenterology 105: 1698-1704, 1993.

77. Lichtenberger LM: The hydrophobic barrier properties of gastrointestinal mucus. Annu Rev Physiol 57: 565-583, 1995.

78. Taylor C, Allen A, Dettmar PW and Pearson JP: The gel matrix of gastric mucus is maintained by a complex interplay of transient and nontransient associations. Biomacromolecules 4: 922-927, 2003.

79. Atuma C, Strugala V, Allen A and Holm L: The adherent gastrointestinal mucus gel layer: Thickness and physical state in vivo. Am J Physiol Gastrointest Liver Physiol 280: G922-G929, 2001.

80. Ermund A, Schütte A, Johansson ME, Gustafsson JK and Hansson GC: Studies of mucus in mouse stomach, small intestine, and colon. I. Gastrointestinal mucus layers have different properties depending on location as well as over the Peyer's patches. Am J Physiol Gastrointest Liver Physiol 305: G341-G347, 2013.

81. Ota $\mathrm{H}$ and Katsuyama T: Alternating laminated array of two types of mucin in the human gastric surface mucous layer. Histochem J 24: 86-92, 1992.

82. Ho SB, Takamura K, Anway R, Shekels LL, Toribara NW and Ota $\mathrm{H}$ : The adherent gastric mucous layer is composed of alternating layers of MUC5AC and MUC6 mucin proteins. Dig Dis Sci 49: 1598-1606, 2004.

83. Hanisch FG, Chai W, Rosankiewicz JR, Lawson AM, Stoll MS and Feizi T: Core-typing of O-linked glycans from human gastric mucins. Lack of evidence for the occurrence of the core sequence Gal1-6GalNAc. Eur J Biochem 217: 645-655, 1993.

84. Phillipson M, Atuma C, Henriksnäs J and Holm L: The importance of mucus layers and bicarbonate transport in preservation of gastric juxtamucosal pH. Am J Physiol Gastrointest Liver Physiol 282: G211-G219, 2002.

85. Schreiber S and Scheid P: Gastric mucus of the guinea pig: Proton carrier and diffusion barrier. Am J Physiol 272: G63-G70, 1997.

86. Johansson M, Synnerstad I and Holm L: Acid transport through channels in the mucous layer of rat stomach. Gastroenterology 119: 1297-1304, 2000.

87. Kouznetsova I, Laubinger W, Kalbacher H, Kalinski T, Meyer F, Roessner A and Hoffmann W: Biosynthesis of gastrokine-2 in the human gastric mucosa: Restricted spatial expression along the antral gland axis and differential interaction with TFF1, TFF2 and mucins. Cell Physiol Biochem 20: 899-908, 2007.

88. Hanisch FG, Bonar D, Schloerer N and Schroten H: Human trefoil factor 2 is a lectin that binds $\alpha$-GlcNAc-capped mucin glycans with antibiotic activity against Helicobacter pylori. J Biol Chem 289: 27363-27375, 2014.

89. Rossez Y, Maes E, Lefebvre Darroman T, Gosset P, Ecobichon C, Joncquel Chevalier Curt M, Boneca IG, Michalski J-C and Robbe-Masselot C: Almost all human gastric mucin O-glycans harbor blood group A, B or $\mathrm{H}$ antigens and are potential binding sites for Helicobacter pylori. Glycobiology 22: 1193-1206, 2012.

90. Van Halbeek H, Gerwig GJ, Vliegenthart JF, Smits HL, Van Kerkhof PJ and Kramer MF: Terminal $\alpha(1 \rightarrow 4)$-linked $\mathrm{N}$-acetylglucosamine: A characteristic constituent of duodenalgland mucous glycoproteins in rat and pig. A high-resolution 'H-NMR study. Biochim Biophys Acta 747: 107-116, 1983. 
91. Gabius $\mathrm{HJ}: \mathrm{Ca}^{2+}$ : mastermind and active player for lectin activity (including a gallery of lectin folds). In: The Sugar Code: Fundamentals of Glycosciences. Gabius HJ (ed). Wiley-VCH, Weinheim, pp269-278, 2009.

92. Westley BR, Griffin SM and May FE: Interaction between TFF1, a gastric tumor suppressor trefoil protein, and TFIZ1, a brichos domain-containing protein with homology to SP-C. Biochemistry 44: 7967-7975, 2005

93. Albert TK, Laubinger W, Müller S, Hanisch F-G, Kalinski T, Meyer $\mathrm{F}$ and Hoffmann W: Human intestinal TFF3 forms disulfide-linked heteromers with the mucus-associated FCGBP protein and is released by hydrogen sulfide. J Proteome Res 9: 3108-3117, 2010

94. Otto WR, Rao J, Cox HM, Kotzian E, Lee CY, Goodlad RA, Lane A, Gorman M, Freemont PA, Hansen HF, et al: Effects of pancreatic spasmolytic polypeptide (PSP) on epithelial cell function. Eur J Biochem 235: 64-72, 1996.

95. Rousseau K, Byrne C, Kim YS, Gum JR, Swallow DM and Toribara NW: The complete genomic organization of the human MUC6 and MUC2 mucin genes. Genomics 83: 936-939, 2004.

96. Bäckström M, Ambort D, Thomsson E, Johansson ME and Hansson GC: Increased understanding of the biochemistry and biosynthesis of MUC2 and other gel-forming mucins through the recombinant expression of their protein domains. Mol Biotechnol 54: 250-256, 2013

97. Joba W and Hoffmann W: Similarities of integumentary mucin B.1 from Xenopus laevis and prepro-von Willebrand factor at their amino-terminal regions. J Biol Chem 272: 1805-1810, 1997.

98. Leir SH and Harris A: MUC6 mucin expression inhibits tumor cell invasion. Exp Cell Res 317: 2408-2419, 2011.

99. Purvis AR, Gross J, Dang LT, Huang R-H, Kapadia M, Townsend RR and Sadler JE: Two Cys residues essential for von Willebrand factor multimer assembly in the Golgi. Proc Nat Acad Sci USA 104: 15647-15652, 2007.

100. Springer TA: von Willebrand factor, Jedi knight of the bloodstream. Blood 124: 1412-1425, 2014.

101. Purvis AR and Sadler JE: A covalent oxidoreductase intermediate in propeptide-dependent von Willebrand factor multimerization. J Biol Chem 279: 49982-49988, 2004.

102. Godl K, Johansson ME, Lidell ME, Mörgelin M, Karlsson H, Olson FJ, Gum JR Jr, Kim YS and Hansson GC: The N terminus of the MUC2 mucin forms trimers that are held together within a trypsin-resistant core fragment. J Biol Chem 277: 47248-47256, 2002

103. Perez-Vilar J and Hill RL: Identification of the half-cystine residues in porcine submaxillary mucin critical for multimerization through the D-domains. Roles of the CGLCG motif in the D1- and D3-domains. J Biol Chem 273: 34527-34534, 1998.

104. Hoffmann W, Jagla W and Wiede A: Molecular medicine of TFF-peptides: From gut to brain. Histol Histopathol 16: 319-334, 2001.

105. Toribara NW, Ho SB, Gum E, Gum JR Jr, Lau P and Kim YS: The carboxyl-terminal sequence of the human secretory mucin, MUC6. Analysis of the primary amino acid sequence. J Biol Chem 272: 16398-16403, 1997.

106.Zhou YF and Springer TA: Highly reinforced structure of a C-terminal dimerization domain in von Willebrand factor. Blood 123: 1785-1793, 2014

107. Perez-Vilar J and Hill RL: The carboxyl-terminal 90 residues of porcine submaxillary mucin are sufficient for forming disulfide-bonded dimers. J Biol Chem 273: 6982-6988, 1998.

108. Perez-Vilar J and Mabolo R: Gel-forming mucins. Notions from in vitro studies. Histol Histopathol 22: 455-464, 2007.

109. Park SW, Zhen G, Verhaeghe C, Nakagami Y, Nguyenvu LT, Barczak AJ, Killeen N and Erle DJ: The protein disulfide isomerase AGR2 is essential for production of intestinal mucus. Proc Natl Acad Sci USA 106: 6950-6955, 2009.

110. Adler KB, Tuvim MJ and Dickey BF: Regulated mucin secretion from airway epithelial cells. Front Endocrinol 4: article 129, 2013.

111. Kaser A, Adolph TE and Blumberg RS: The unfolded protein response and gastrointestinal disease. Semin Immunopathol 35: 307-319, 2013

112. Gupta A, Wodziak D, Tun M, Bouley DM and Lowe AW: Loss of anterior gradient 2 (Agr2) expression results in hyperplasia and defective lineage maturation in the murine stomach. J Biol Chem 288: 4321-4333, 2013.

113. Mayadas TN and Wagner DD: Vicinal cysteines in the prosequence play a role in von Willebrand factor multimer assembly. Proc Natl Acad Sci USA 89: 3531-3535, 1992.
114. Huang RH, Wang Y, Roth R, Yu X, Purvis AR, Heuser JE, Egelman EH and Sadler JE: Assembly of Weibel-Palade body-like tubules from N-terminal domains of von Willebrand factor. Proc Natl Acad Sci USA 105: 482-487, 2008.

115. Ambort D, Johansson ME, Gustafsson JK, Nilsson HE, Ermund A, Johansson BR, Koeck PJB, Hebert H and Hansson GC: Calcium and $\mathrm{pH}$-dependent packing and release of the gel-forming MUC2 mucin. Proc Natl Acad Sci USA 109: 5645-5650, 2012.

116. Perez-Vilar J, Eckhardt AE, DeLuca A and Hill RL: Porcine submaxillary mucin forms disulfide-linked multimers through its amino-terminal D-domains. J Biol Chem 273: 14442-14449, 1998.

117. Dang LT, Purvis AR, Huang RH, Westfield LA and Sadler JE: Phylogenetic and functional analysis of histidine residues essential for $\mathrm{pH}$-dependent multimerization of von Willebrand factor. J Biol Chem 286: 25763-25769, 2011.

118. Chin WC, Quesada I, Nguyen T and Verdugo P: Oscillations of $\mathrm{pH}$ inside the secretory granule control the gain of $\mathrm{Ca}^{2+}$ release for signal transduction in goblet cell exocytosis. Novartis Found Symp 248: 132-141, discussion 141-149, 277-282, 2002.

119. Dickson EJ, Duman JG, Moody MW, Chen L and Hille B: OraiSTIM-mediated $\mathrm{Ca}^{2+}$ release from secretory granules revealed by a targeted $\mathrm{Ca}^{2+}$ and $\mathrm{pH}$ probe. Proc Natl Acad Sci USA 109: E3539-E3548, 2012

120. Borges R, Domínguez N, Estévez-Herrera J, Pereda D and Machado JD: Vesicular $\mathrm{Ca}^{2+}$ mediates granule motion and exocytosis. Cell Calcium 51: 338-341, 2012.

121. Perez-Vilar J, Olsen JC, Chua M and Boucher RC: pH-dependent intraluminal organization of mucin granules in live human mucous/goblet cells. J Biol Chem 280: 16868-16881, 2005.

122. Perez-Vilar J: Mucin granule intraluminal organization. Am J Respir Cell Mol Biol 36: 183-190, 2007.

123. Verdugo P: Mucin exocytosis. Am Rev Respir Dis 144: S33-S37, 1991.

124. Verdugo P: Supramolecular dynamics of mucus. Cold Spring Harb Perspect Med 2: 2, 2012.

125. Chen EY, Yang N, Quinton PM and Chin W-C: A new role for bicarbonate in mucus formation. Am J Physiol Lung Cell Mol Physiol 299: L542-L549, 2010

126. Thim L, Madsen F and Poulsen SS: Effect of trefoil factors on the viscoelastic properties of mucus gels. Eur J Clin Invest 32: 519-527, 2002

127. Bansil R, Celli JP, Hardcastle JM and Turner BS: The influence of mucus microstructure and rheology in Helicobacter pylori infection. Front Immunol 4: 310, 2013.

128. Kjellev S, Nexø E, Thim L and Poulsen SS: Systemically administered trefoil factors are secreted into the gastric lumen and increase the viscosity of gastric contents. Br J Pharmacol 149: 92-99, 2006

129. Tanaka S, Podolsky DK, Engel E, Guth PH and Kaunitz JD Human spasmolytic polypeptide decreases proton permeation through gastric mucus in vivo and in vitro. Am J Physiol 272: G1473-G1480, 1997.

130. Jagla W, Wiede A, Kölle S and Hoffmann W: Differential expression of the TFF-peptides xP1 and xP4 in the gastrointestinal tract of Xenopus laevis. Cell Tissue Res 291: 13-18, 1998.

131. Botzler C, Oertel M, Hinz M and Hoffmann W: Structure of the Xenopus laevis TFF-gene xP4.1, differentially expressed to its duplicated homolog XP4.2. Biochim Biophys Acta 1489: 345-353, 1999.

132. Crouzier T, Beckwitt $\mathrm{CH}$ and Ribbeck K: Mucin multilayers assembled through sugar-lectin interactions. Biomacromolecules 13: 3401-3408, 2012.

133. Peterson AJ, Menheniott TR, O'Connor L, Walduck AK, Fox JG, Kawakami K, Minamoto T, Ong EK, Wang TC, Judd LM, et al: Helicobacter pylori infection promotes methylation and silencing of trefoil factor 2, leading to gastric tumor development in mice and humans. Gastroenterology 139: 2005-2017, 2010.

134. Yang I, Nell S and Suerbaum S: Survival in hostile territory: The microbiota of the stomach. FEMS Microbiol Rev 37: 736-761, 2013.

135. Paulsen FP, Schaudig U, Fabian A, Ehrich D and Sel S: TFF peptides and mucins are major components of dacryoliths. Graefes Arch Clin Exp Ophthalmol 244: 1160-1170, 2006.

136. Rinnert M, Hinz M, Buhtz P, Reiher F, Lessel W and Hoffmann W: Synthesis and localization of trefoil factor family (TFF) peptides in the human urinary tract and TFF2 excretion into the urine. Cell Tissue Res 339: 639-647, 2010. 
137. Reeves EP, Ali T, Leonard P, Hearty S, O'Kennedy R, May FEB, Westley BR, Josenhans C, Rust M, Suerbaum S et al: Helicobacter pylori lipopolysaccharide interacts with TFF1 in a pH-dependent manner. Gastroenterology 135: 2043-2054, 2054. e2041-2042, 2008.

138. Hoffmann W and Hauser F: Biosynthesis of frog skin mucins: Cysteine-rich shuffled modules, polydispersities and genetic polymorphism. Comp Biochem Physiol B 105: 465-472, 1993

139. De Giorgio MR, Yoshioka M, Riedl I, Moreault O, Cherizol R-G, Shah AA, Blin N, Richard D and St-Amand J: Trefoil factor family member 2 (Tff2) KO mice are protected from high-fat diet-induced obesity. Obesity 21: 1389-1395, 2013.
140. Sacchettini JC, Baum LG and Brewer CF: Multivalent proteincarbohydrate interactions. A new paradigm for supermolecular assembly and signal transduction. Biochemistry 40: 3009-3015, 2001.

141. Rabinovich GA, Toscano MA, Jackson SS and Vasta GR: Functions of cell surface galectin-glycoprotein lattices. Curr Opin Struct Biol 17: 513-520, 2007. 